\title{
Prepatellar Morel-Lavallée effusion
}

\author{
Noushin Yahyavi-Firouz-Abadi • Jennifer L. Demertzis
}

Received: 29 December 2011 / Revised: 2 March 2012 / Accepted: 6 March 2012 /Published online: 18 April 2012

(C) ISS 2012

Keywords Degloving $\cdot$ MRI $\cdot$ Injury

\section{Diagnosis}

Prepatellar Morel-Lavallée effusion (closed degloving injury)

\section{Discussion}

Lateral radiograph of the left knee shows prepatellar soft tissue swelling. MR images demonstrate a T2-hyperintense unilocular prepatellar fluid collection located between the subcutaneous fat and underlying fascia. The collection extends beyond the transverse and craniocaudal boundaries of the prepatellar bursa, with the medial and lateral margins reaching the level of the femoral epicondyles at the midcoronal plane, and the superior and inferior margins extending from the mid-thigh to beyond the tibial tubercle. These findings are indicative of a prepatellar Morel-Lavallée effusion and are distinguished from prepatellar bursitis by

The case presentation can be found at doi:10.1007/s00256-012-1399-0.

N. Yahyavi-Firouz-Abadi $(\bowtie)$

Mallinckrodt Institute of Radiology,

510 South Kingshighway Boulevard, Campus Box 8131, St Louis, MO 63110, USA

e-mail: yahyavin@mir.wustl.edu

\section{J. L. Demertzis}

Division of Musculoskeletal Radiology,

Mallinckrodt Institute of Radiology,

510 South Kingshighway Boulevard, Campus Box 8131, St Louis, MO 63110, USA

e-mail: demertzisj@mir.wustl.edu location beyond the anatomic confines of the prepatellar bursa. Quadriceps muscle signal intensity is normal, excluding muscle contusion as the cause of the patient's pain. Other post-traumatic subcutaneous lesions in the differential diagnosis such as fat necrosis, pseudolipoma, and coagulopathy-related hematoma are unlikely given the anatomic location, imaging characteristics, and clinical history [1]. The patient was successfully treated with activity restriction, ice, and compression wraps.

Maurice Morel-Lavallée first described closed degloving injuries of the hip and pelvis in 1853 [2]. Excessive shearing force or repetitive compressive trauma causes separation of the skin and subcutaneous fat from underlying deep fascia resulting in disruption of perforating vessels and formation of fluid collections containing blood, fat, and lymph [1-3]. Morel-Lavallée lesions adjacent to the greater trochanter, proximal femur, buttock, and lower back are well known $[4,5]$, and MR imaging has an established role in their diagnosis. The appearance of Morel-Lavallée effusions on MRI depends on lesion acuity and the amount of blood product, fat, and lymph tissue within it [1]. Mellado et al. described six types of Morel-Lavallée effusions ranging from seroma to infected collections, with a unilocular T2 hyperintense fluid collection being the most common finding of the basic subtypes [1]. Neither blood product, fat, nor a fibrous pseudocapsule was identified in this particular case. Of these findings, the presence of an enhancing pseudocapsule has prognostic value, suggesting possible benefit of therapeutic aspiration or debridement to facilitate resolution of the lesion $[1,2]$.

Despite the established diagnosis of Morel-Lavallée effusion in the pelvis and hips, its occurrence in the prepatellar region has only recently been described in the orthopedic [6, 7] and radiology literature [8,9]. A recent case series of 24 
national football league players revealed a shearing blow from the playing field as the most common cause of a prepatellar degloving injury, with successful treatment with compression wrap and cryotherapy in most cases and recurrent aspiration and occasionally sclerotherapy in refractory cases [6]. In this study, most cases of Morel-Lavallée effusion were diagnosed clinically by identification of a fluctuant suprapatellar fluid collection often extending medially and laterally at the mid- to distal thigh, a location distinct from the prepatellar bursa. Cadaveric studies have demonstrated that the normal prepatellar bursa does not extend beyond the mid-coronal plane medially or laterally or to the mid-thigh proximally [10]. A more recent study evaluated MR imaging features of prepatellar Morel-Lavallée injuries in four young wrestlers with emphasis on differentiating prepatellar bursitis from Morel-Lavallée effusion [8]. The authors found MR a valuable diagnostic addition to size criteria and physical examination used in the orthopedic literature by demonstrating the extent of the fluid collection beyond the boundaries of a normal or slightly swollen bursa. While follow-up imaging and clinical response to steroid injection may also be useful in distinguishing between these two entities [8], the distinction may not be clinically necessary as treatment strategies and outcomes are often the same. However, in cases where a fibrous pseudocapsule has developed, or where there are clinical or imaging findings suggestive of infection such as pseudocapsule enhancement, internal septations, and inflammation of the adjacent fatty tissue and fascia, this distinction has therapeutic value, suggesting possible benefit of aspiration or debridement of the collection $[1,2]$.

Relatively recent descriptions of prepatellar Morel-Lavallée effusions in the radiology literature and a few published imaging descriptions indicate that this entity may be underdiagnosed. In this report, we emphasize the importance of recognizing prepatellar Morel-Lavallée effusions, especially in contact sports such as football and wrestling.

\section{References}

1. Mellado JM, Bencardino JT. Morel-Lavallée lesion: review with emphasis on MR imaging. Magn Reson Imaging Clin N Am. 2005; $13: 775-82$.

2. Hak DJ, Olson SA, Matta JM. Diagnosis and management of closed internal degloving injuries associated with pelvic and acetabular fractures: the Morel-Lavallée lesion. J Trauma. 1997;42:1046-51.

3. Hudson DA, Knottenbelt JD, Krige JE. Closed degloving injuries: results following conservative surgery. Plast Reconstr Surg. 1992;89:853-5.

4. Mellado JM, Perez del Palomar L, Diaz L, Ramos A, Sauri A. Long-standing Morel-Lavallée lesions of the trochanteric region and proximal thigh: MRI features in five patients. AJR Am J Roentgenol. 2004;182:1289-94.

5. Parra JA, Fernandez MA, Encinas B, Rico M. Morel-Lavallée effusions in the thigh. Skeletal Radiol. 1997;26:239-41.

6. Tejwani SG, Cohen SB, Bradley JP. Management of MorelLavallée lesion of the knee: twenty-seven cases in the national football league. Am J Sports Med. 2007;35:1162-7.

7. Powers ML, Hatem SF, Sundaram M. Morel-Lavallée lesion. Orthopedics. 2007;30(250):322-3.

8. Borrero CG, Maxwell N, Kavanagh E. MRI findings of prepatellar Morel-Lavallée effusions. Skeletal Radiol. 2008;37:4515.

9. Ciaschini M, Sundaram M. Radiologic case study. Prepatellar Morel-Lavallée lesion. Orthopedics. 2008;31(626):719-21.

10. Dye SF, Campagna-Pinto D, Dye CC, Eisman T. Soft-tissue anatomy anterior to the human patella. J Bone Joint Surg Am. $2003 ; 85: 1012-7$. 